\title{
LA URETRO-CISTOGRAFIA EN LA INCONTINENCIA DE ORINA
}

\author{
Doctores Víctor Velásquez y Aron Vantman
}

La frecuencia de la incontinencia de orina en la mujer hace de esta afección un tema de permanente actualidad, ya que del conocimiento de la fisiopatología y de los medios de diagnóstico depende, en gran parte, la adecuada conducta terapéutica.

Muchas han sido las definiciones propuestas para este síndrome génito-urinario; nosotros estimamos más razonable la de incontinencia esfinteriana, por ser la mejor que se adapta a la discusión de tema.

Sin entrar a estudiar los variados factores etiopatogénicos que intervienen en la continencia vesical, quisiéramos mencionar brevemente la importancia que tienen los factores locales relacionados con procesos patológicos del aparato génito-urinario, los factores generales relacionados con estados de desequilibrio hormonal y los factores neurológicos, constituídos por el importante capítulo de la vejiga neurogénica.

El conocimiento de la fisiopatología de la continencia urinaria en la mujer se ha obtenido mediante los estudios anatómicos y radiológicos, principalmente, y han sido, estos últimos, los que han dado los aportes más recientes y más importante para el tratamiento quirúrgico; conocimientos derivados del estudio de la topografía vesical, de su sistema esfinteriano y de los cambios fisiológicos que se producen cuando se desencadena el mecanismo de la micción.

El mecanismo de continencia vésicouretral está en estrecha relación con el músculo detrusor vesical, que forma la casi totalidad de la pared de este órgano. Su contracción produce la presión necesaria para el vaciamiento vesical. En la región del cuello las fibras del detrusor, que es un músculo liso, se distribuyen en forma especial para formar el esfínter interno o liso, que está constituído por dos asas de diferente dirección y desarrollo, que se han designado con los nombres de asa retractora a la que abraza al cuello por su cara posterior, y asa protractora a aquella que abraza al cuello por su cara anterior.

* Clínica Ginecológica Universitaria. Cátedra de Ginecología. Profesor Juan Wood. Santiago, Chile. 
En la región uretral, que queda inmediatamente por debajo del esfínter liso, se halla ubicado el esfínter estriado, que constituye para el primero un excelente medio de sostén, que le impide, cuando es normal, desplazarse hacia atrás o hacia abajo en la pelvis. El esfínter estriado está constituído por tres formaciones musculares escalonadas a lo largo de la uretra, y ellas dependen de la musculatura estriada del periné anterior. En la parte superior estas formaciones musculares provienen del haz pubo-coxígeo del elevador del ano,

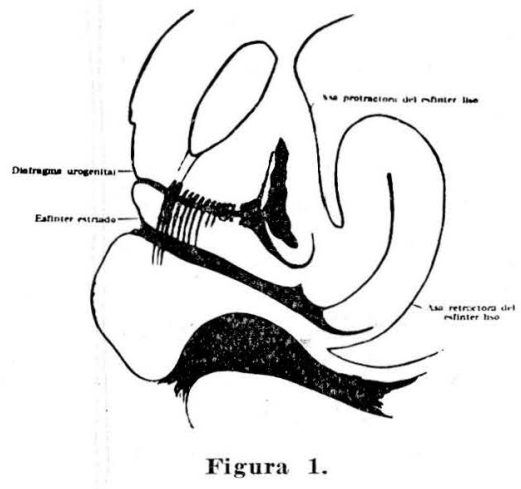

a cuyo nivel forman una especie de cincha que sirve de sostén al esfínter liso. Radiológicamente se ha observado que su contracción voluntaria determina la aplicación de la pared posterior de la uretra sobre la anterior y una angulación de ella hacia adelante. En la parte media el esfínter estriado está constituído por haces dependientes de los músculos transverso profundo y aponeurosis perineal media, entre cuyas hojas queda incluído, le forman a la uretra un anillo circular. En la parte inferior, este esfínter queda formado por elementos musculares provenientes del bulbo e isquio cavernoso. La contracción de estas fibras provoca la evacuación final del conducto uretral y además una angulación de la uretra hacia atrás en forma opuesta a la que producen la contracción de los haces pubocoxígeos del elevador del ano. Esta doble angulación del conducto que lo transforma, por el aspecto, en una $\mathrm{S}$, es también un factor de continencia vesical, como lo son también la longitud del conducto uretral, la implantación tangencial de la uretra en la vejiga y la existencia a lo largo de la uretra de plexos venosos sub-mucosos, formaciones eréctiles cuya atrofia en la mujer menopáusica favorecería la aparición de incontinencia urinaria.

Es, por lo tanto, en la armonía que exista entre los factores dinámicos representados por un esfínter interno con buena tonicidad y un adecuado sostén que impida su desplazamiento, y de los factores estáticos ya mencionados, donde reside el fundamento de la fisiología del aparato uretro-vesical.

Toda incontinencia de orina debe ser estudiada conjuntamente por el ginecólogo y el urólogo. Mediante la cistoscopia será posible establecer la existencia de lesiones crónicas de tipo inflamatorio que afectan a la uretra y zonas vecinas al cuello vesical; lesiones que pueden revestir diversos grados de intensidad y que, no obstante su conocimiento desde antiguo, su correcta interpretación constituye una adquisición relativamente reciente. El desconocimiento de estas lesiones inflamatorias de la uretra posterior y del trígono vesical, que se traducen en la clínica por incontinencia de orina y que en un 
alto porcentaje de casos acompañan a un prolapso genital, será muchas veces responsable de la persistencia de una incontinencia de orina, aun cuando el cirujano haya empleado una correcta técnica quirúrgica para el tratamiento de la distopia genital. En una revisión practicada por uno de nosotros en 1960, se encontró en 594 enfermas con prolapso genital $244(41 \%)$ con trastornos urinarios; de éstas 174 pacientes tenían incontinencia de orina y 70 disuria solamente. De las 174 enfermas con incontinencia de orina se practicó en 110 examen uretro-cistoscópico, comprobándose en 59 signos evidentes de uretrotrigonitis, en 31 manifestaciones de uretritis posterior y en 20 indemnidad del segmento uretro-vesical.

Además del estudio clínico que incluye el interrogatorio, que puede orientar al diagnóstico de fístula uro-genital o de incontinencia por falla esfinteriana, el examen ginecológico, que precisa el grado de prolapso cuando esta distopia se acompaña de incontinencia urinaria y con ello el tipo de operación que logre mejorar ambos cuadros, hay que recurrir a medios de examen indispensables tales como la citología vaginal, que nos informa sobre el nivel estrogénico; la cistometría, que nos permitirá estudiar las vejigas neurogénicas; la cistoscopia, que nos revela la existencia de los procesos inflamatorios que asientan en la mucosa uretral y/o vesical, que se traduce por falsas incontinencias, y cuyo tratamiento debe ser previo a la corrección quirúrgica del prolapso genital, y uretro-cistografía.

La uretro-cistografía es el método de exploración y diagnóstico que más ha contribuído al estudio de la anatomía topográfica, al esclarecimiento de la fisiopatología de este segmento urinario y al diagnóstico de la incontinencia esfinteriana o verdadera de orina.

En la mujer normal, la base de la vejiga en la radiografía frontal se encuentra inmediatamente por encima de la sínfisis pubiana; al iniciarse la micción, la base de ella desciende y la zona del cuello adopta la forma en punta. Hemos observado, igual que Muellner, que en condiciones normales el esfínter queda inmediatamente por delante de la región en que la vejiga recibe la mayor acción del impulso producido por la prensa abdominal.

En la incontinencia de orina, la vejiga está más descendida con respecto a la sínfisis pubiana y presenta, incluso, en reposo, la típica figura de la forma en punta de la vejiga en micción. Con el esfuerzo, la base desciende, agudizándose mucho más el ángulo formado por sus paredes laterales. Mediante la radiografía en posición oblicua se puede apreciar que la base adopta la forma de embudo, quedando allí incluída la zona esfinteriana. Con el esfuerzo desciende la vejiga, la zona esfinteriana desciende también, ocupando la porción de más declive de la vejiga. Junto con el descenso, la zona esfinteriana sufre un desplazamiento hacia atrás, con lo que esta región viene a quedar justamente en el sitio en que la vejiga recibe de lleno la trasmisión del impulso de la prensa abdominal. La uretra también se desplaza hacia abajo, continuándose en una misma línea con la base de la vejiga, con lo cual desaparece el ángulo uretrovesical. Esta última modificación es la 


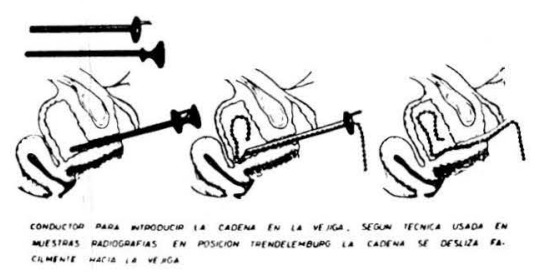

Figura 2.

que se observa más frecuentemente y es la más importante en los casos de incontinencia urinaria.

Estos hechos, que la uretrocistografía pone de relieve, tienen gran importancia por cuanto en la cirugía de esta afección será preciso corregir las alteraciones topográficas del esfínter interno, modificar los soportes esfinterianos en tal forma que cualquier esfuerzo no lo empuje hacia la pelvis y fijar el cuello vesical en la parte anterior del pubis para que no reciba directamente la acción impulsiva de la prensa abdominal.

Nosotros practicamos la uretro-cistografía utilizando como medio de contraste el yoduro de sodio al $10 \%$.

Cateterizamos la vejiga con un uretroscopio lubricado con una crema anestésica, colocamos la paciente en posición de Trendelenburg, con ello se facilita enormemente la introducción de una cadenilla de $25 \mathrm{~cm}$. de largo, con esferitas metálicas de más o menos tres $\mathrm{mm}$. de diámetro y separadas por eslabones de uno o dos $\mathrm{mm}$. Estando ya colocada la cadenilla en la vejiga, retiramos el uretroscopio e inyectamos en ella, mediante una sonda de Nélaton, 200 a 240 c.c. de la solución de yoduro de sodio. Las placas radiográficas en número de cuatro, las tomamos en posición de pie: dos en sentido anteroposterior, de las cuales una en reposo y otra bajo la acción de un esfuerzo. Las otras dos placas se toman en posición oblicua y bajo las mismas indicaciones.

Del estudio de 24 pacientes con incontinencia de orina atendidas en la Clínica Ginecológica Universitaria en los últimos 3 años se encontraron los siguientes resultados:

\begin{tabular}{llr} 
& & \multicolumn{3}{c}{ Pacientes } \\
Incontinencia de orina pura & $\ldots$ & 4 \\
Prolapso genital incompleto & $\ldots$ & 17 \\
Prolapso genital completo & $\ldots . .$. & 3
\end{tabular}

En las radiografías frontal con esfuerzo se observó descenso de la base vesical en 20 de estas pacientes; deformación en forma de embudo en 15. En las radiografías en oblicua y con es-

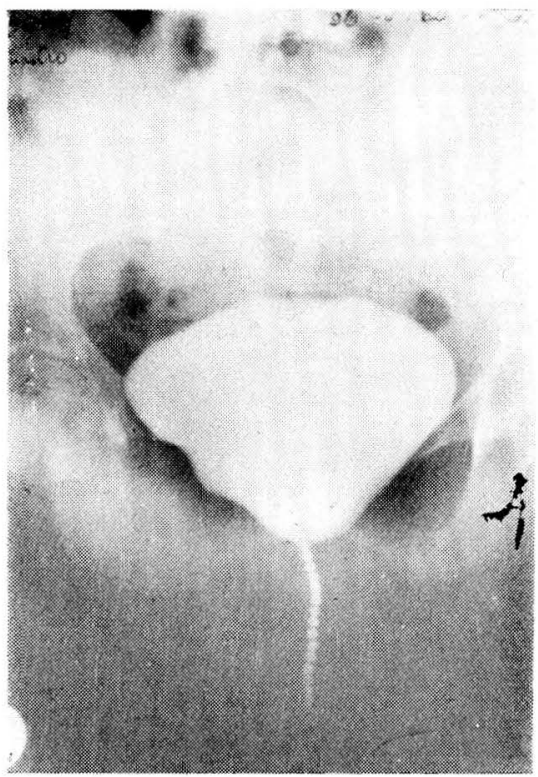

Figura 3. Frontal: en reposo. 


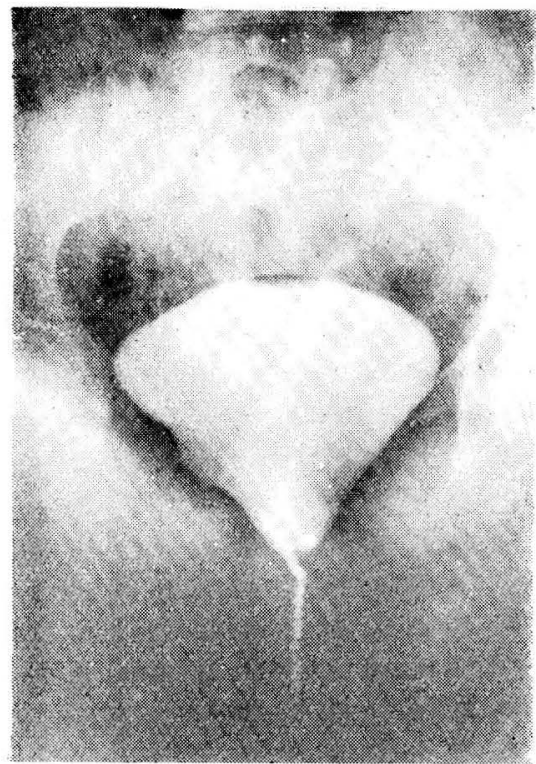

Figura 4. Frontal: con esfuerzo.

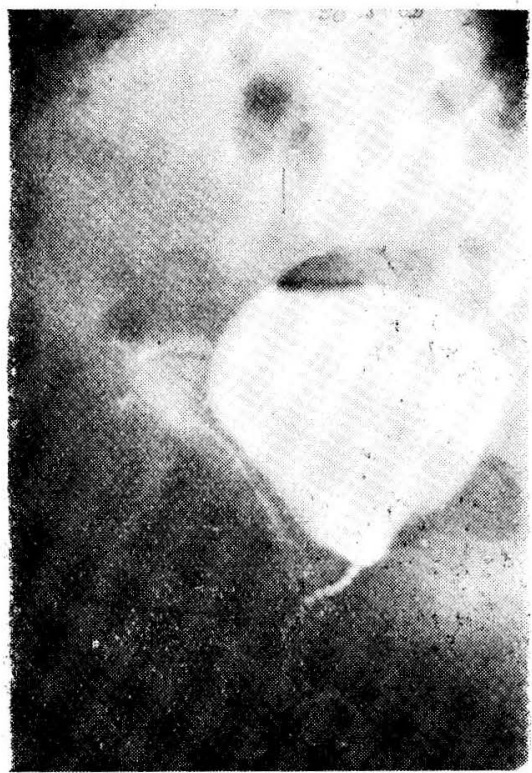

Figura 5. Oblicua: en reposo.

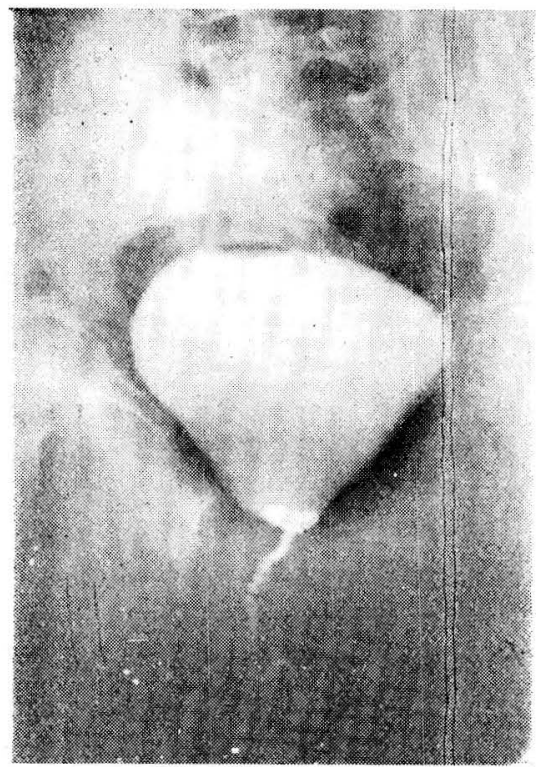

Figura 6. Oblicua: con esfuerzo.

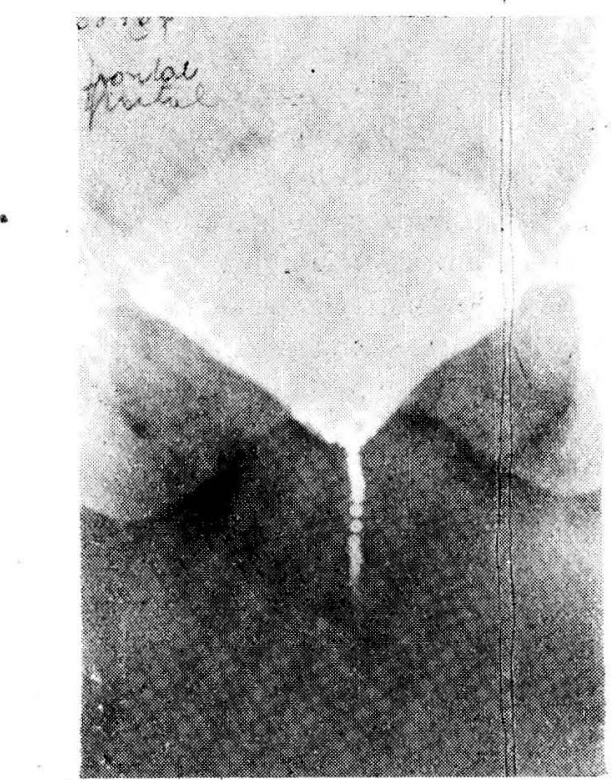

Figura 7. Frontal: en reposo. 


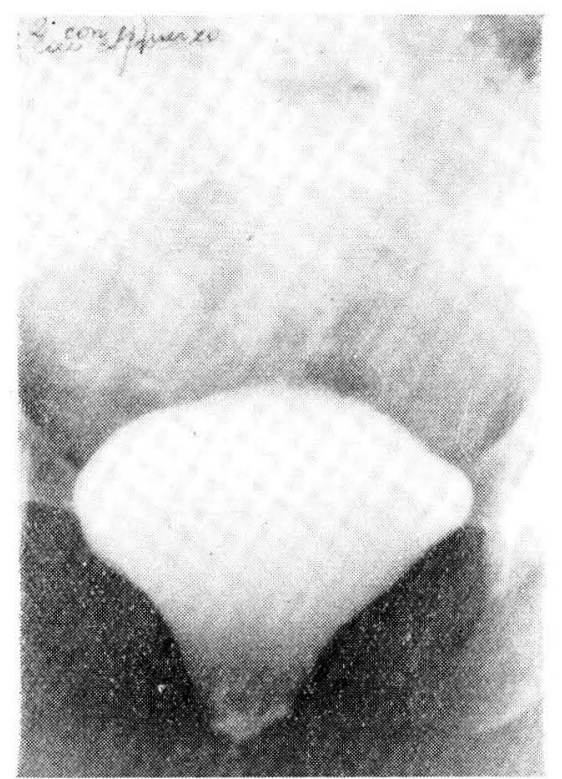

Figura 8. Frontal: con esfuerzo.

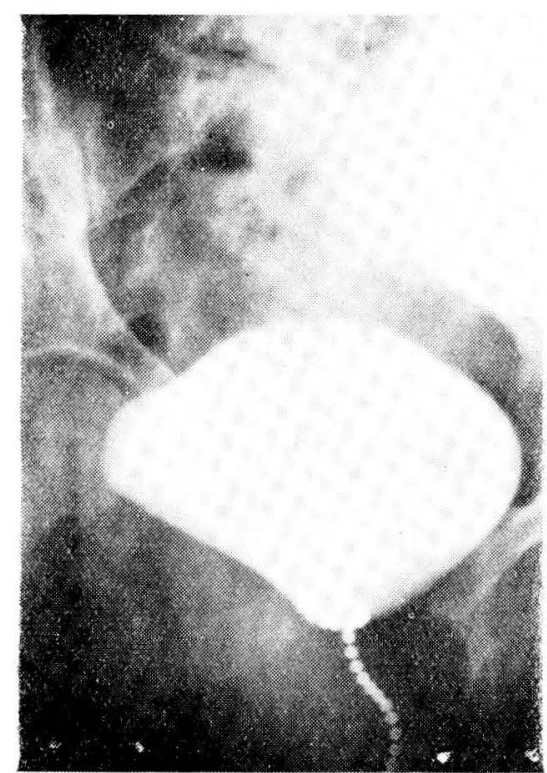

Figura 9. Oblicua: en reposo.

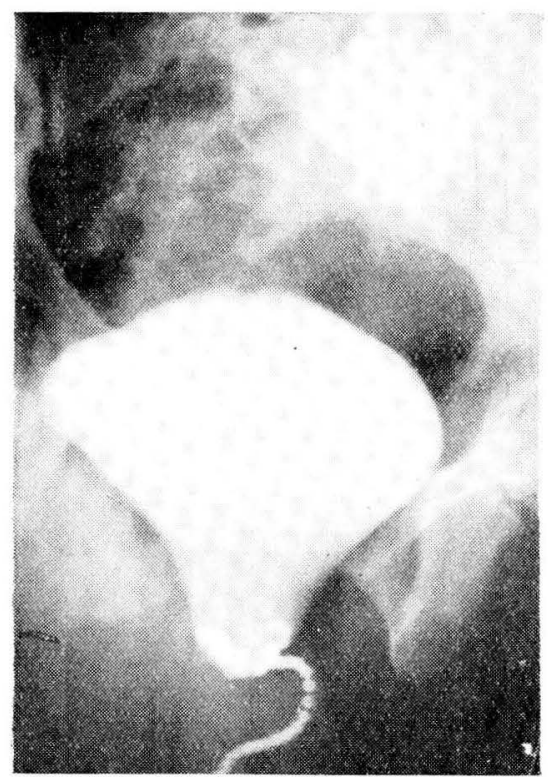

Figura 10. Oblicua con esfuerzo.

fuerzo se observó en 9 pacientes la desaparición del ángulo uretro-vesical posterior.

\section{RESUMEN Y CONCLUSIONES}

Se analizan los factores que intervienen en la incontinencia esfinteriana, los que se clasifican en locales, generales y neurológicos.

Se estudia los mecanismos de continencia vésico-uretral, los métodos de examen, destacando la importancia que tiene la uretrocistografía en el estudio de la anatomía topográfica, en la fisiopatología, diagnóstico y tratamiento.

Se describe la técnica empleada aconsejando obtener 4 placas radiográficas por enferma en posición frontal y oblicua, y en reposo y con esfuerzo. 
Se analizan 24 pacientes con inconti- esfuerzo y la desaparición del ángulo nencia urinaria y se concluye la impor- uretro-vesical en oblicua en el tratatancia que tienen el descenso de la base miento quirúrgico de esta afección. de la vejiga en la radiografía frontal con

$\begin{array}{lllllllllllll}\text { B } & \text { I } & \mathbf{B} & \mathbf{L} & \mathbf{I} & \mathbf{O} & \mathbf{G} & \mathbf{R} & \mathbf{A} & \mathbf{F} & \mathbf{I} & \mathbf{A}\end{array}$

1. HOdGkinso C. P.: Am. J. Obst. Gyn. 65:560, 1953. 73:518, 1957.

2. MUellner, S. R.: Surg. Gyn. Obst. 88:237, 1949. 114:568, 1962.

3. Les Troubles Fonetionnelles Urétro-vesicaux in Gynécologie. Masson et Cie. Paris, 1960.

4. ERCOLE, R.: VI Congreso Americano y III Argentino de Urología. T. II. B. Aires, 1957.

5. BISQUert J. y Velasquez V.: VI Congreso Americano y III Argentino de Urología. T. II. B. Aires, 1957.

6 Wood J., velasquez V. Bisquert J.: Bol. Soc. Chil. de Obst. y Ginec. 24:192, 1959.

7. Velasquez, V.: Bol. Soc. Chil. Obst. y Ginec. (en prensa). 